1 Identification of Female Sex Pheromone for Monitoring the Barred

2 Tooth Striped Moth, Trichopteryx polycommata, a Priority

3 Conservation Species

4

5 Ashen Oleander ${ }^{1}$ David R. Hall ${ }^{2}$ Daniel P. Bray ${ }^{2}$ Joseph P. J. Burman ${ }^{1}$

$6 \quad{ }^{1}$ Ecology Research Group, Canterbury Christ Church University, North Holmes Road, 7 Canterbury, CT11QU, UK

$8 \quad{ }^{2}$ Natural Resources Institute (NRI), University of Greenwich, Medway Campus, Central 9 Avenue, Chatham Maritime, Kent, ME4 4TB, UK

10

11 Joseph P. J. Burman

12 joseph.burman@canterbury.ac.uk

13 https://orcid.org/0000-0003-3888-4238 Tel: +447720290812

\title{
15 Abstract
}

16 Pheromone-baited traps can be excellent tools for sensitive detection of insects of

17 conservation concern. Here, identification of the sex pheromone of Trichopteryx polycommata (Denis \& Schiffermüller, 1775), an under-recorded UK priority species, is reported. In analyses of extracts of the pheromone glands of female T. polycommata by gas chromatography coupled to electroantennographic recording from the antenna of a male moth, a single active component was detected. This was identified as (Z,Z)-6,9nonadecadiene (Z,Z6,9-19:H) by comparison of its mass spectrum and retention times with those of the synthetic standard. In a pilot field trial in Kent, UK, T. polycommata males were caught in pheromone traps baited with lures loaded with $1 \mathrm{mg}$ and $2 \mathrm{mg}(Z, Z)-6,9-19: \mathrm{H}$.

Optimum lure loading was identified in a further five trials in Kent, Sussex and Lancashire where lures of $0,0.001,0.01,0.1,1,2,5$ and $10 \mathrm{mg}$ loadings were tested. Traps baited with 1 to $10 \mathrm{mg}$ of ZZ6,9-19:H caught significantly more $T$. polycommata than traps baited with 0 $\mathrm{mg}$ and $0.001 \mathrm{mg}$. In a pilot survey of T. polycommata using pheromone lures around Morecambe Bay, UK, $T$. polycommata males were captured at 122 new sites within the three 
30 counties where trials took place, demonstrating the potential of pheromone monitoring to increase knowledge of abundance, distribution and ecology of this elusive species.

Key Words (Z,Z)-6,9-nonadecadiene, electroantennography, insect conservation, lure, detection of endangered species, biodiversity, mapping indicator species, live-catching pheromone traps.

\section{Introduction}

Biodiversity loss is a global crisis (Brooks et al. 2012; Jenkins 2003) which continues despite international agreements to promote conservation (Larigauderie et al. 2012; Santamaría and Méndez 2012; Waldron et al. 2013). The rate of loss of invertebrate populations exceeds that of vertebrates and vascular plants, possibly by several orders of magnitude (Conrad et al. 2006; Dunn 2005; Samways 2007; Thomas et al. 2004). Decline of insect populations is of particular concern, as they are a vital component of ecosystems. Insects provide stability in ecosystems, recycle nutrients and transfer energy between trophic levels. They also supply many ecosystem services essential to humanity, particularly pollination and biological pest control, as well as being of inherent cultural value (Fonseca 2009; Kellert 1993; Kim 1993; Littlewood et al. 2012). However, efforts to conserve insect populations are complicated by a lack of knowledge and data on threatened species. This is due in part to a lack of tools which are suitably sensitive to detect and monitor limited populations of small organisms (Cardoso et al. 2011),

Recently, tools employing pheromones have been developed for monitoring insects of conservation value, including Elater ferrugineus (Linnaeus, 1758), Osmoderma eremita (Scopoli, 1763) (Larsson and Svensson 2009; Larsson et al. 2003), and the luna moth Actias luna (L.) (Millar et al. 2016). Historically, pheromone traps have been employed as sensitive, species-specific tools for monitoring pest species in and around crops. The same strategy could equally be applied to detection and monitoring of threatened insect populations (Andersson et al. 2014; Larsson \& Svensson 2009; Musa et al. 2013). Pheromone monitoring has been shown to be more sensitive and cost-effective than traditional sampling methods and could potentially contribute to solving some of the problems experienced in insect conservation (Andersson et al. 2014; Larsson \& Svensson 2009; Musa et al. 2013; Svensson et al. 2009). However, such an approach requires that an attractive pheromone is produced by 
62

the target species, and that it can be chemically characterized and produced in sufficient quantities for field use.

The aim of this study was to develop and test a pheromone-based system for detecting and monitoring populations of Trichopteryx polycommata (Denis \& Schiffermüller 1775) (JNCC 2007) is now only found in a few locations in Kent, Sussex, North Hampshire, Wiltshire, Lancashire and South Cumbria, with limited records from Dorset, Herefordshire, Norfolk and Scotland (Wigglesworth et al. 2018). The larvae feed on wild privet (Ligustrum vulgare) (Linnaeus, 1758) and ash (Fraxinus excelsior) (Linnaeus, 1758) (Wigglesworth et al. 2018), and have also been known to feed on species of Lonicera (Choi 2007).

Trichopteryx polycommata is therefore a bioindicator for presence of $L$. vulgare, an important food plant for many species, and could be used to assess the potential impact of ash dieback on insect communities. Trichopteryx polycommata also supports a host-specific parasitoid wasp Earinus transversus Lyle (Hymenoptera: Braconidae: Agathidinae) found only in the UK, and rediscovered after 100 years in 2005 (Shaw 2010).

Species-specific monitoring and a need to gain a better understanding of population distribution, status and ecology are crucial to conservation of T. polycommata (JNCC 2010). The moths are infrequently caught in light traps (Wigglesworth et al. 2018), and the best current technique for detection is to search for adults resting on L. vulgare after dark (Wigglesworth et al. 2018). Here, we collected and identified a putative sex pheromone produced by $T$. polycommata, and confirmed that it elicits is a physiological response through electroantennography. Lures releasing the pheromone were formulated and tested through pilot studies to determine whether they attract $T$. polycommata moths, presented alone and in combination with funnel traps. In a second experiment, we examined the effect of amount of pheromone loaded into lures on number of moths caught. Finally, we conducted a preliminary field survey with pheromone-baited traps, to assess their usefulness in detecting populations of T. polycommata.

\section{Methods and Materials}

Insect Sourcing and Sample Collection Three adult female and four male T. polycommata moths were collected by torch light and netting from Seaford Head Nature Reserve, Sussex $(50.756995 \mathrm{~N}, 0.13722479 \mathrm{E})$ on 23 March 2016 . The moths were kept in a refrigerator at 5 
${ }^{\circ} \mathrm{C}$ in individual plastic containers $(17.8 \times 11.5 \times 4.4 \mathrm{~cm})$. Pieces of damp cotton wool were placed in each container to maintain humidity and provide a drinking source. The next day at $1000 \mathrm{~h}$ the females were removed from the refrigerator and placed in a dark, controlledtemperature room at $10{ }^{\circ} \mathrm{C}$ to mimic the conditions under which the moths are found to be most active. At $1230 \mathrm{~h}$ gland extracts were taken from two live females who had been observed calling for approximately $90 \mathrm{~min}$. During calling, females swayed their abdomen back and forth while the pulsing pheromone gland was exposed, at which point it was excised with a pair of microscissors. Excised glands were placed immediately into individual glass vials (1.1mL $12 \mathrm{~mm}$ x 32mm; Fisher Scientific, Leicestershire, UK) each containing $10 \mu 1$ of hexane (HPLC Plus; Sigma-Aldrich). After $10 \mathrm{~min}$ the hexane was removed using a pipette and retained in a separate vial. A second wash was performed with another $10 \mu l$ of hexane and stored separately. Glands were retained individually in vials containing $10 \mu 1$ of hexane. All samples were placed in the freezer at $-20{ }^{\circ} \mathrm{C}$ until use.

\section{Analyses by Gas Chromatography linked to Electroantennographic Detection (GC-EAD)}

Male T. polycommata moths used for GC-EAD were kept in a refrigerator at $5{ }^{\circ} \mathrm{C}$ in individual plastic containers $(0.8 \times 11.5 \times 4.4 \mathrm{~cm})$ containing damp cotton wool. Individuals were removed from the refrigerator $2 \mathrm{~h}$ before use to allow them to acclimatize to room temperature. Insects were then anesthetized using carbon dioxide, and the head removed under a dissecting microscope with a razor blade. A borosilicate glass capillary electrode (ID 0.86mm, Warner Instruments, Hamden, CT06514), pulled to a fine tip and filled with $0.1 \mathrm{M}$ $\mathrm{KCl}$ containing $1 \%$ polyvinylpyrrolidine as electrolyte, was inserted into the back of the head. The electrode and head were then mounted onto a silver wire held within an electrode holder connected to the earth probe of a portable EAG amplifier (INR-2, Syntech, formerly Hilversum, The Netherlands, now Kirchzarten, Germany). A similar electrode mounted onto the $\mathrm{x} 10$ recording preamplifier was then brought into contact with the distal tip of the antenna.

Samples were presented to antennal preparations via a gas chromatograph (HP6890, Agilent Technologies, Stockport, Cheshire, UK) fitted with DB-WAX and DB1 fused silica capillary columns (30 m x $0.32 \mathrm{~mm}$ i.d. x $0.25 \mu$ film thickness; Supelco, Gillingham, Dorset, UK). The eluents from the columns were combined with a glass Y-piece into a length (10 $\mathrm{cm}$ ) of deactivated fused silica capillary and then split 50:50 using a glass Y-piece to equal lengths of deactivated fused silica tubing leading to the flame ionization detector (FID) and 
via a heated $\left(250^{\circ} \mathrm{C}\right)$ transfer line into silanized glass tube ( $4 \mathrm{~mm}$ i.d.) delivering a continuous flow of air $(200 \mathrm{ml} / \mathrm{min})$ over the antennal preparation. Gland extracts $(1 \mu \mathrm{l})$ were injected at $220^{\circ} \mathrm{C}$ in splitless mode onto the DB-WAX column, with the oven temperature held for 2 min at $50{ }^{\circ} \mathrm{C}$ before increasing at $20^{\circ} \mathrm{C} \min ^{-1}$ or $10{ }^{\circ} \mathrm{C} \mathrm{min}^{-1}$ to $250{ }^{\circ} \mathrm{C}$ and held for $5 \mathrm{~min}$. Carrier gas was helium at continuous flow of $2.4 \mathrm{ml} / \mathrm{min}$. The EAG signal was digitized by connecting the amplifier as a GC detector and this and the simultaneous FID signal were captured and analyzed using EZchrom Elite (Version 3.3.1, Agilent Technologies). Antennal preparations were only moved under the air flow outlet once the solvent peak had eluted. Two of the four males survived so two EAD runs of the first wash of the gland extract from the same female moth were carried out using an antenna from each male in turn. Standard $n$ alkanes ( $\mathrm{C} 8$ to $\mathrm{C} 24)$ were run under the same conditions to calculate retention indices.

\section{Analyses by Gas Chromatography coupled to Mass Spectrometry (GC-MS) Pheromone} gland extracts were analyzed by gas chromatography-mass spectrometry (GC-MS) on a CP3800 GC coupled directly to a Saturn 2200 MS (Varian, now Agilent Technologies) in electron impact mode. The GC was equipped with a polar DB-Wax column and non-polar VF5 column (Agilent; $30 \mathrm{~m} \times 0.25 \mathrm{~mm}$ i.d. $\times 0.25 \mu$ film thickness) connected to the transfer line via a Quick-Switch Valve. The GC was programmed at $40{ }^{\circ} \mathrm{C}$ for $2 \mathrm{~min}$, then increased by $10{ }^{\circ} \mathrm{C} \mathrm{min}^{-1}$ to $240{ }^{\circ} \mathrm{C}$ and held for $5 \mathrm{~min}$. Injections were made in splitless mode at 220 ${ }^{\circ} \mathrm{C}$ and the transfer line temperature was $250{ }^{\circ} \mathrm{C}$. Carrier gas was helium at a constant flow of $1 \mathrm{ml} / \mathrm{min}$. Gas chromatography retention times were converted to retention indices by comparison with the retention times of $n$-alkanes as above.

Field Trials $(Z, Z)-6,9-$ Nonadecadiene $(Z Z 6,9-19: H ; \geq 98 \%$ pure by GC-MS analysis on the polar GC column) was obtained from Pherobank (Wijk bij Duurstede, The Netherlands). Lures were prepared by loading the required amount in hexane solution $(100 \mu l)$ onto rubber septa (13 mm diameter, Sigma Aldrich, Gillingham, Dorset, UK). Once the hexane had evaporated, lures were wrapped in aluminum foil and placed in the freezer until required.

For a preliminary field trial, lures were loaded with $1 \mathrm{mg}$ or $2 \mathrm{mg}$ ZZ6,9-19:H. In the field, lures were attached to garden canes approximately $1 \mathrm{~m}$ above ground level, the height at which T. polycommata rest on privet hedges. The lures were tested in this way at the following 17 key British locations known to contain T. polycommata populations in Sussex 
(50.827194N, 0.455016W), Inverness (57.425511N, 4.499708W), Norfolk (52.402082N, $0.754747 \mathrm{E} ; 52.509296 \mathrm{~N}, 0.627334 \mathrm{E} ; 52.466495 \mathrm{~N}, 0.769076 \mathrm{E} ; 52.478686 \mathrm{~N}, 0.786043 \mathrm{E}$; $52.488902 \mathrm{~N}, 0.614333 \mathrm{E} ; 52.568607 \mathrm{~N}, 0.596493 \mathrm{E} ; 52.451878 \mathrm{~N}, 0.942289 \mathrm{E} ; 52.402082 \mathrm{~N}$, $0.754747 \mathrm{E} ; 52.468944 \mathrm{~N}, 0.772028 \mathrm{E})$; Argyll and Bute $(56.558925 \mathrm{~N}, 5.253752 \mathrm{~W}$; $56.558678 \mathrm{~N}, 5.254284 \mathrm{~W})$; Yorkshire (54.082715N, 2.022893W; $54.084423 \mathrm{~N}, 2.021212 \mathrm{~W}$; $54.137356 \mathrm{~N}, 2.036545 \mathrm{~W}$ and $54.083614 \mathrm{~N}, 2.022893 \mathrm{~W}$ ) between 28 March and 11 May 2017. Searches for T. polycommata by torchlight are typically carried out between $1900 \mathrm{~h}$ and $2130 \mathrm{~h}$ when the moths can be seen resting on $L$. vulgare. Participants given lures to test without traps trialed the lures during this time period. Lures were tested for 15-20 min before being moved to a new location at least $50 \mathrm{~m}$ away.

In a parallel trial, two economy funnel traps (Oecos Ltd, Kimpton, UK; height $22 \mathrm{~cm}$, diam. $13 \mathrm{~cm}$ ), one baited with the $1 \mathrm{mg}$ lure the other baited with the $2 \mathrm{mg}$ lure, were placed at St Margaret's Bay, Kent (51.141445N, 1.372182E). The traps were hung from a large $L$. vulgare bush approximately $1 \mathrm{~m}$ above the ground and approximately $5 \mathrm{~m}$ apart from each other on 21 March 2017. The traps were checked daily between 22-28 March 2017 and any moths caught were released within a $5 \mathrm{~m}$ radius of the trap. This inevitably meant that there would be some recaptures of individual males. Ideally recaptured moths would have been identified by mark recapture methods, but we were not able to mark captured moths due to restrictions on handling this rare species. Recapture rates in moth pheromones tend to be fairly low after a few days of recapture (Oleander et al. 2018), so the overall effect can likely be considered negligible.

To investigate the effect of lure loading on catches, lures were loaded with $0.001 \mathrm{mg}$, $0.01 \mathrm{mg}, 0.1 \mathrm{mg}, 1 \mathrm{mg}, 2 \mathrm{mg}, 5 \mathrm{mg}$ and $10 \mathrm{mg}$ of ZZ6,9-19H. Control lures were made by adding $100 \mu \mathrm{l}$ of hexane to the rubber septum. The field trials were carried out at five locations: St Margaret's Bay, Kent (51.141445N, 1.372182E); Seaford Head, Sussex (50.756995N, 0.137225E); Warton Crag, Lancashire (54.148923N, 2.783226W); Roudsea, Lancashire (54.234726N, 3.026337W); Challan Hall, Lancashire (54.188482N, 2.808341W and 54.195082N, 2.802492W); and Sizergh, Lancashire (54.285892N, 2.788926W). Trials took place between 29 March - 4 April 2017 in Kent; 30 March and 13 April 2017 in Sussex and between 13-25 April 2017 in Lancashire. At each location, eight economy funnel traps (Oecos Ltd) $\mathrm{K}$ were baited with the lures. The traps were positioned $2 \mathrm{~m}$ apart and were placed in the order of lowest loading to highest. In Kent the traps were arranged in two parallel lines, each line containing four traps positioned $2 \mathrm{~m}$ apart and the lines were also $2 \mathrm{~m}$ 
apart. In Sussex and Lancashire, on each site the traps were arranged in an approximate semicircle and were $2 \mathrm{~m}$ apart. Traps were placed in this close proximity due to the limited size of the locations, which are narrow open pathways through a woodland. The traps were checked daily and any moths caught were identified and released within a $5 \mathrm{~m}$ radius of the traps. Traps were moved round one position daily to reduce any positional effect. As a precautionary measure, the traps were removed every two or three days for two days to ensure the local population of moths would have the opportunity to mate.

For statistical analysis, at each of the six sites at which lures were tested, the total number of $T$. polycommata captured by each lure loading was divided by number of nights of trapping to give mean catch night ${ }^{-1}$. The resultant means were transformed to $\log (n+1)$ and entered as the dependent variable into a linear model with site (six level factor) and lure loading (eight level factor) as independent variables. Significance of terms within the model were assessed by $F$ tests, with Tukey's test $(P<0.05)$ of estimated marginal means used to identify significant differences between lure loadings, controlling for effect of site. Estimated marginal means (and 95\% confidence intervals) of catch night ${ }^{-1}$ for each lure loading were back-transformed onto the original scale for presentation. All data analysis was performed in R (R Core Team, 2018, Lenth 2019)

T. polycommata Survey A field survey was carried out in order to establish the potential for increasing detection of $T$. polycommata moths using a pheromone-based method of sampling. Pheromone traps baited with $2 \mathrm{mg}$ lures were placed overnight at 168 locations at 102 sites in Morecambe Bay between 11 April - 1 May 2017. T. polycommata had previously been recorded at 26 of the 168 locations. One economy funnel trap (Oecos Ltd, UK) was used per location. Each trap was hung on a tree or bush approximately $1 \mathrm{~m}$ above the ground. The traps were set in position by 17:00 $\mathrm{h}$ and checked by 11:00 $\mathrm{h}$ the following day. Any moths caught were identified and released into suitable vegetation on site. Maps of distribution were produced using ArcMap 10.2.2 (ESRI (Environmental Systems Resource Institute) 2014).

\section{Results}

Pheromone Identification A single, reproducible response was observed in GC-EAD analyses of ovipositor extracts of female $T$. polycommata run using a polar GC column. The 
antenna of a male moth responded to a putative major sex pheromone component (Fig. 1) at Retention Index (RI) 1964. The amount present was up to $150 \mathrm{ng}$ per ovipositor. In GC-MS analyses this major peak had RI 1950 on the polar column and 1869 on the non-polar column. The mass spectrum (Fig. 2) showed a probable molecular ion at $\mathrm{m} / \mathrm{z}, 264$ and base peak at $\mathrm{m} / \mathrm{z}$ 67. The data were consistent with those for a straight-chain, 19-carbon hydrocarbon with two non-conjugated double bonds, most likely in the 6,9-positions as the 3,6-configuration would have been expected to give a strong ion at $m / z 79$ (e.g. Yamamoto et al. 2008). Synthetic (Z,Z)-6,9-nonadecadiene (ZZ6,9-19:H) was subsequently obtained and had identical mass spectrum (Fig. 2) and RI's to the natural compound, although insects were not available by then to test the EAG response to the synthetic compound.

Field Trials In the first trial with volunteers and lures suspended on canes, T. polycommata males were observed to be attracted to the $1 \mathrm{mg}$ and $2 \mathrm{mg}$ ZZ6,9-19:H lures at 50.827194N, $0.455016 \mathrm{~W}$ and $54.082715 \mathrm{~N}, 2.022893 \mathrm{~W}$ but not at any of the other sites. In the parallel live trapping trial, one male $T$. polycommata was caught in the trap baited with the $1 \mathrm{mg}$ lure while 16 males were caught in the trap baited with the $2 \mathrm{mg}$ lure. No other species of moths were caught in these traps.

In the trial to compare catches with different lure loadings, controlling for a significant effect of trapping location $\left(F_{5,35}=8.7, P<0.001\right)$, an overall significant effect of pheromone loading was found on mean catch night ${ }^{-1}\left(F_{7,35}=11.1, P<0.001\right.$, Fig. 3). Traps baited with 1 to $10 \mathrm{mg}$ of ZZ6,9-19:H caught significantly more $T$. polycommata than traps baited with $0 \mathrm{mg}$ and $0.001 \mathrm{mg}$. Traps baited with $10 \mathrm{mg}$ ZZ6,9-19:H also caught significantly more $T$. polycommata than traps baited with $0.01 \mathrm{mg}$.

No other species were attracted to the lures in Kent and Sussex, but in Lancashire $T$. carpinata (Borkhausen, 1794) and Chloroclystis v-ata (Haworth, 1809) (Lepidoptera: Geometridae) were caught in the pheromone baited traps, although in much lower numbers than $T$. polycommata (67 and 1 respectively, compared to $514 T$. polycommata).

It was observed on 31 March 2017 at Seaford Head that at 2130 h no T. polycommata had been caught in the pheromone traps, but by $1000 \mathrm{~h}$ the following morning 61 had been caught. During the Lancashire field trials, it was observed that activity at the pheromone traps began at $0045 \mathrm{~h}$ and lasted for approximately $45 \mathrm{~min}$. 
255 Survey of T. polycommata. The pilot study increased the number of records of $T$.

1 2256 polycommata from 107 to 881 in the region and the number of known T. polycommata sites 3
4 57 from 48 to 88 . Fig. 4 shows the known distribution and abundance of $T$. polycommata in the 5
6 258 Morecambe Bay area before 2017 and after the pilot pheromone study. 


\section{Discussion}

Prior to this study, the recommended way of surveying for T. polycommata was to search $L$. vulgare bushes after dark by torchlight looking for adults resting on the twigs. The results presented here demonstrate that pheromone-baited traps could provide a more practical and sensitive method of detection. (Z,Z)-6,9-nonadecadiene (ZZ6,9-19:H) was identified as a component of the female sex pheromone of this species, which attracts male moths in the field. This is the first pheromone component to be identified in the genus Trichopteryx which contains 11 other species. Given the small numbers of individuals available for this study and the somewhat artificial conditions used prior to gland extraction, the possibility of there being additional components in the complete pheromone cannot be excluded. However, only a single reproducible EAG response was recorded from males in GC-EAD analyses of pheromone gland extracts.

(Z,Z)-6,9-Nonadecadiene has been identified as a sex pheromone or attractant in one member of the Arctiidae family and 14 members of the Geometridae family in the subfamilies Alsophilinae, Ennominae and Larentiinae (Pherobase, 2017). Of these species the following occur in the UK: Alcis repandata (Linnaeus, 1758), Bupalus piniaria (Linnaeus, 1758), Campaea margaritata (Linnaeus, 1761), Ecliptopera silaceata (Dennis \& Schiffermuller, 1775), Operophtera fagata (Scharfenberg, 1805), Epirrhoe alternata (Muller, 1764) and Epirrhoe tristata (Linnaeus, 1758) (Bogenschuetz et al. 1985; Chittamuru 2000; Francke et al. 1998; Millar et al. 1992; Subchev et al. 1986; Szocs et al. 2004; Wong et al. 1985). None of these species was caught in the traps baited with ZZ6,9-19:H in our studies, probably due, at least in part, to differences in flight seasons and distributions. Trichopteryx polycommata flies from March to early May while A. repandata flies in June and July, B. piniarius flies in May and June, C. margaritata flies from June to September, E. silaceata flies from May to September, O. fagata flies from October to December, E. alternata flies from May to September and E. tristata flies from May to July (Kimber 2018).

In Kent and Sussex, only T. polycommata were caught in the pheromone traps. However, in Lancashire adults of $T$. carpinata, the only other species in the Trichopteryx genus found in the UK, were also caught. Despite being more common than $T$. polycommata, T. carpinata were trapped in lower numbers. This suggests that Z,Z6,9-19:H may not be the complete pheromone blend for T. carpinata, and additional pheromone components may play a role in maintaining reproductive isolation from $T$. polycommata. Moths of the two species 
have different markings and can be distinguished and identified by eye. Thus, cross-attraction does not present a problem for monitoring $T$. polycommata using pheromone lures, and indeed, traps baited with this compound can potentially be used to monitor both species to some extent.

The limited data acquired so far on the timing of response of $T$. polycommata males to the pheromone indicate that this is much later than the times when surveys have previously been carried out. Searches for T. polycommata by torchlight are typically carried out between $1900 \mathrm{~h}$ and $2130 \mathrm{~h}$ when the moths can be seen resting on L. vulgare. However, it is probable that male moths are responding to the pheromone after this time, which may explain why few moths were observed flying to the lures in the initial tests with volunteers. Consequently, in order to use the lures effectively they must be deployed overnight in pheromone traps. For successful trapping programs, optimum trap height for this species still needs to be established, as height and trap design can have significant influence on number caught (Yonce et al. 1976). If a pheromone trap is not available or appropriate, observations in this study suggest that the lures should be used after midnight. Further investigation is needed to identify when the males are most responsive to the pheromone and therefore the optimum time to use the lures.

The lures loaded with $10 \mathrm{mg}$ ZZ6,9-19:H attracted the highest numbers of $T$. polycommata, but not significantly more than those attracted to lures containing 1, 2 and 5 $\mathrm{mg}$. We therefore recommend the lower loadings for monitoring this species. Using $2 \mathrm{mg}$ pheromone lures to survey for T. polycommata increased the number of records in Morecambe Bay, Lancashire from 107 to 881 and the number of sites where T. polycommata has been recorded from 48 to 88 .

Using pheromone traps requires less survey effort than searching by torchlight, so a greater number of sites can be surveyed and therefore knowledge of distribution, status and ecology of the species can be improved (Burman et al. 2016; Giangregorio 2015; Zauli et al. 2014). This has been demonstrated with Synanthedon vespiformis, and saproxylic beetles Osmoderma eremita and Elater ferrugineus (Burman et al. 2016; Giangregorio 2015; Zauli et al. 2014). Improved knowledge of insect distribution can be used to help inform management practices and to predict the effects of factors such as habitat fragmentation (Giangregorio 2015; Zauli et al. 2014). The Biodiversity Action Plan (BAP) for T. polycommata identifies a need to encourage survey work to gain a better understanding of the moth's distribution and this pilot study clearly shows that pheromone monitoring achieved this. The pheromone lures 
enable low-effort species-specific monitoring to be carried out by volunteers and conservation organizations. Such activities will support other BAP actions, including understanding the ecology of T. polycommata, and better managing the sites where it is found.

In light of this successful pilot study, a nationwide survey of $T$. polycommata using pheromone lures is now being conducted with a number of conservation organizations across the UK. In most European countries, the population trends of T. polycommata are unknown or assumed to be stable, except in Belgium where the species is reported to be no longer present (JNCC 2010). International surveys using pheromone lures would contribute to $T$. polycommata conservation programs across Europe, and could lead to rediscovery of populations in places where it was previously thought to have become extinct.

Acknowledgements We would like to thank Butterfly Conservation UK for recruiting field recorders and helping to coordinate distribution of lures. We would particularly like to thank Tony Davis for obtaining insect material, Martin Wain, Liz Davidson the numerous field recorders who volunteered to help with survey work in Morecambe Bay and Lancashire, and Colin Whiteman and for his help in Sussex trials. Thanks also go to the landowners who allowed access to their property in aid of insect conservation research, and Canterbury Christ Church University for funding the field research. 


\section{References}

Andersson K, Bergman KO, Andersson F, Hedenström E, Jansson N, Burman J, Winde I, Larsson MC, Milberg P (2014) High-accuracy sampling of saproxylic diversity indicators at regional scales with pheromones: The case of Elater ferrugineus (Coleoptera, Elateridae). Biol Conserv 171:156-166. doi: 10.1016/j.biocon.2014.01.007

Bogenschütz H, Knauf W, Tröger EJ, Bestmann HJ, Vostrowsky O (1985) Pheromones 49: males of Geometridae caught by C19-polyenes in pine stands. Z Angew Entomol 100:349-354

Brooks DR, Bater JE, Clark SJ, Monteith DT, Andrews C, Corbett SJ, Beaumont DA, Chapman JW (2012) Large carabid beetle declines in a United Kingdom monitoring network increases evidence for a widespread loss in insect biodiversity. J Appl Ecol 49:1009-1019. doi: 10.1111/j.1365-2664.2012.02194.x

Burman J, Westerberg L, Ostrow S, Ryrholm N, Bergman KO, Winde I, Nyabuga FN, Larsson MC, Milberg P (2016) Revealing hidden species distribution with pheromones: the case of Synanthedon vespiformis (Lepidoptera: Sesiidae) in Sweden. J Insect Conserv 20:11-21. doi: 10.1007/s10841-015-9835-9

Cardoso P, Erwin TL, Borges PA V, New TR (2011) The seven impediments in invertebrate conservation and how to overcome them. Biol Conserv 144:2647-2655. doi: 10.1016/j.biocon.2011.07.024

Chittamuru S (2000) Studies on the female sex pheromone of the pine looper moth, Bupalus piniaria L.(Lepidoptera: Geometridae). Thesis University of Greenwich, UK

Choi SW (2007) Taxonomic study of the genus Trichopteryx Hübner (Lepidoptera: Geometridae) in Korea. Entomol Res. 37: 46-53. doi: 10.1111/j.17485967.2007.00052.x

Conrad KF, Warren MS, Fox R, Parsons MS, Woiwod IP (2006) Rapid declines of common, widespread British moths provide evidence of an insect biodiversity crisis. Biol Conserv 132:279-291. doi: 10.1016/j.biocon.2006.04.020

Dunn RR (2005) Modern insect extinctions, the neglected majority. Conserv Biol 19:10301036 
ESRI (Environmental Systems Resource Institute) (2014) ArcMap 10.2. ESRI, Redlands, California.

Fonseca CR (2009) The silent mass extinction of insect herbivores in biodiversity hotspots. Conserv Biol 23:1507-1515. doi: 10.1111/j.1523-1739.2009.01327.x

Francke W, Brunnemann U, Bergmann J, Plass E (1998) Semiochemistry at junctions, volatile compounds from desert locusts, caddisflies and geometrid moths. In: Int. Conf. Insect Phero. pp 71-73

Giangregorio P (2015) Updated distribution of Osmoderma eremita in Abruzzo (Italy) and agro-pastoral practices affecting its conservation (Coleoptera: Scarabaeidae).

Fragmenta Entomolica 47:139-146. doi: doi.org/10.4081/fe.2015.142

Jenkins M (2003) Prospects for biodiversity. Science 302:1175-1177. doi:

10.1126/science. 1088666

JNCC (2007) UK BAP priority terrestrial invertebrate species. http://jncc.defra.gov.uk/page5169. Accessed 3 Aug 2018

JNCC (2010) Trichopteryx polycommata version 2. http://jncc.defra.gov.uk/_speciespages/616.pdf. Accessed 3 Aug 2018

Kadej M, Zając K, Ruta R, Gutowski JM, Tarnawski D, Smolis A, Olbrycht T, Malkiewicz A, Myśków E, Larsson MC, Andersson F (2014) Sex pheromones as a tool to overcome the Wallacean shortfall in conservation biology: a case of Elater ferrugineus Linnaeus, 1758 (Coleoptera: Elateridae). J Insect Conserv 25-32. doi: 10.1007/s10841-014-9735-4

Kellert SR (1993) Values and perceptions of invertebrates. Conserv Biol 7:845-855. doi: 10.1046/j.1523-1739.1993.07040845.x

Kim KC (1993) Biodiversity, conservation and inventory: why insects matter. Biodivers Conserv 2:191-214

Kimber I (2018) UKMoths | Guide to the moths of Great Britain and Ireland. In: UKMoths. http://www.ukmoths.org.uk/. Accessed 3 Aug 2018

Larigauderie A, Prieur-Richard AH, Mace GM, Lonsdale M, Mooney HA, Brussaard L, Cooper D, Cramer W, Daszak P, Díaz S, Duraiappah A (2012) Biodiversity and 
404

ecosystem services science for a sustainable planet: The DIVERSITAS vision for 2012-20. Curr Opin Env Sust 4:101-105. doi: 10.1016/j.cosust.2012.01.007

Larsson MC, Hedin J, Svensson GP, Tolasch T, Francke W (2003) Characteristic odor of Osmoderma eremita identified as a male-released pheromone. J Chem Ecol 29:575587. doi: 10.1023/A:1022850704500

Larsson MC, Svensson GP (2009) Pheromone monitoring of rare and threatened insects: Exploiting a pheromone-kairomone system to estimate prey and predator abundance. Conserv Biol 23:1516-1525. doi: 10.1111/j.1523-1739.2009.01263.x

Lenth R (2019) emmeans: Estimated Marginal Means, aka Least-Squares Means. R package version 1.3.3.

Littlewood N, Stewart AJ, Woodcock B (2012) Science into practice - how can fundamental science contribute to better management of grasslands for invertebrates? Insect Conserv Diver 5:1-8. doi: 10.1111/j.1752-4598.2011.00174.X

Millar JG, Giblin M, Barton D, Underhill EW (1992) Sex pheromone components of the geometrid moths Lobophora nivigerata and Epirrhoe sperryi. J Chem Ecol 18:10571068. doi: 10.1007/BF00980062

Millar JG, Haynes KF, Dossey AT, McElfresh JS, Allison JD (2016) Sex attractant pheromone of the luna moth, Actias luna (Linnaeus). J Chem Ecol 42:869-876. doi: $10.1007 / \mathrm{s} 10886-016-0751-6$

Musa N, Andersson K, Burman J, Andersson F, Hedenström E, Jansson N, Paltto H, Westerberg L, Winde I, Larsson MC, Bergman KO (2013) Using sex pheromone and a multi-scale approach to predict the distribution of a rare saproxylic beetle. PLoS ONE 8:. doi: 10.1371/journal.pone.0066149

Oleander A, Burman J, Buswell V (2018) 'Fool me once, but rarely fool me twice': Recapture rates and the effect of lure-ageing in pheromone traps for the burnet moth Zygaena filipendulae (Linnaeus, 1758) (Lepidoptera: Zygaenidae). Entomol Gaz 69:31-42. doi: 10.31184/G00138894.691.1636

R Core Team (2018) R: A language and environment for statistical computing. R Foundation for Statistical Computing, Vienna, Austria. URL https://www.R-project.org/.

Samways MJ (2007) Insect conservation: a synthetic management approach. Annu Rev Entomol 52:465-487. doi: 10.1146/annurev.ento.52.110405.091317 
Santamaría L, Méndez PF (2012) Evolution in biodiversity policy - current gaps and future needs. Evol Appl 5:202-218. doi: 10.1111/j.1752-4571.2011.00229.x

Shaw M (2010) Rediscovery of Earinus transversus Lyle (Hymenoptera: Braconidae: Agathidinae), a parasitoid of Trichopteryx polycommata (Denis and Schiffermuller)(Lepidoptera). In: Entomologist's Record and Journal of Variation. http://repository.nms.ac.uk/id/eprint/495. Accessed 3 Aug 2018

Subchev MA, Ganev JA, Vostrowsky O, Bestmann HJ (1986) Screening and use of sex attractants in monitoring of Geometrid moths in Bulgaria. Z Naturforsch - Section C J Biosci 41:1082-1086. doi: 10.1515/znc-1986-11-1223

Svensson GP, Oleksa A, Gawroński R, Lassance JM, Larsson MC (2009) Enantiomeric conservation of the male-produced sex pheromone facilitates monitoring of threatened European hermit beetles (Osmoderma spp.). Ent Exp Applic 133:276-282. doi: 10.1111/j.1570-7458.2009.00923.x

Szőcs G, Tóth M, Kárpáti Z, Zhu J, Löfstedt C, Plass E, Francke W (2004) Identification of polyenic hydrocarbons from the northern winter moth, Operophtera fagata, and development of a species specific lure for pheromone traps. Chemoecology 14:53-58. doi: 10.1007/s00049-003-0258-9

Thomas JA, Telfer MG, Roy DB, Preston CD, Greenwood JJ, Asher J, Fox R, Clarke RT, Lawton JH (2004) Comparative losses of British butterflies, birds, and plants and the global extinction crisis. Science 303:1879-1881. doi: 10.1126/science.1095046

Waldron A, Mooers AO, Miller DC, Nibbelink N, Redding D, Kuhn TS, Roberts JT, Gittleman JL (2013) Targeting global conservation funding to limit immediate biodiversity declines. Proc Natl Acad Sci USA 110:1-5. doi: 10.5061/dryad.p69t1

Wigglesworth T, Parsons M, Warren M (2018) Barred Tooth Striped Moth. http://butterflyconservation.org/files/barred_tooth-striped-psf.pdf. Accessed 3 Aug 2018

Wong JW, Underhill EW, MacKenzie SL, Chisholm MD (1985) Sex attractants for Geometrid and Noctuid moths - Field trapping and electroantennographic responses to triene hydrocarbons and monoepoxydiene derivatives. J Chem Ecol 11:727-756. doi: 10.1007/BF00988302

Yamamoto M, Yamakawa R, Oga T, Takei Y, Kinjo M, Ando T (2008) synthesis and chemical characterization of hydrocarbons with a 6,9,11-, 3,6,9,11-, or 1,3,6,9- 
polyene system, pheromone candidates in Lepidoptera. J Chem Ecol 34:1057-1064.

Yonce CE, Gentry CR, Tumlinson JH, Doolittle RE, Nielsen DG (1976) Lesser peachtree borer: Influence of trap height, substrates, concentration, and trap design on capture of male moths with females and with a synthetic pheromone. Env Entomol, 5: 417-420. doi: 10.1093/ee/5.3.417

Zauli A, Chiari S, Hedenström E, Svensson GP, Carpaneto GM (2014) Using odour traps for population monitoring and dispersal analysis of the threatened saproxylic beetles Osmoderma eremita and Elater ferrugineus in central Italy. J Insect Conserv 18:801813. doi: 10.1007/s10841-014-9687-8 


\section{Figure Captions}

478 Fig.1 Coupled gas chromatography-electroantennogram analyses of pheromone gland extract 479 from female Trichopteryx polycommata with antenna from male moth. Fig. 1(a) shows 480 complete analysis and (b) expanded portion with single EAG response to peak at $10.05 \mathrm{~min}$ 481 (run with temperature program of $20^{\circ} \mathrm{C}$ min-1); Fig. 1(c) additional runs with the same 482 extract and antenna of second male moth showing response to peak at $15.04 \mathrm{~min}$ (run with 483 temperature program of $10^{\circ} \mathrm{C}$ min-1). In each, top trace is the EAG response from the male 484 moth antenna; bottom trace is the GC-FID trace.

485 Fig.2 Mass spectra of compound in pheromone gland extract from female Trichopteryx polycommata (upper) and synthetic (Z,Z)-6.9-nonadecadiene (lower)

487 Fig 3. Mean catch night ${ }^{-1}( \pm 95 \% \mathrm{CI})$ of $T$. polycommata at six sites using traps baited with 488 lures loaded with varying amounts of (Z,Z)-6,9-nonadecadiene. Trap catches were $\log (\mathrm{n}+1)$ 489 transformed for analysis and back-transformed to the original scale for presentation. Different 490 letters indicate significant differences in mean catches (Tukey's test, $P<0.05$ )

491 Fig.4 Map of known geographical distribution of Trichopteryx polycommata in Morecombe 492 Bay, UK, before and after pheromone survey work in 2017. Circles are proportional to the 493 number of moths caught at any particular location. White circles represent trap catches at 494 locations where the species had already been recorded prior to the 2017 pheromone survey. 495 Black circles represent trap catches at locations where the moth has never been recorded 496 before but was attracted in the pheromone survey. 

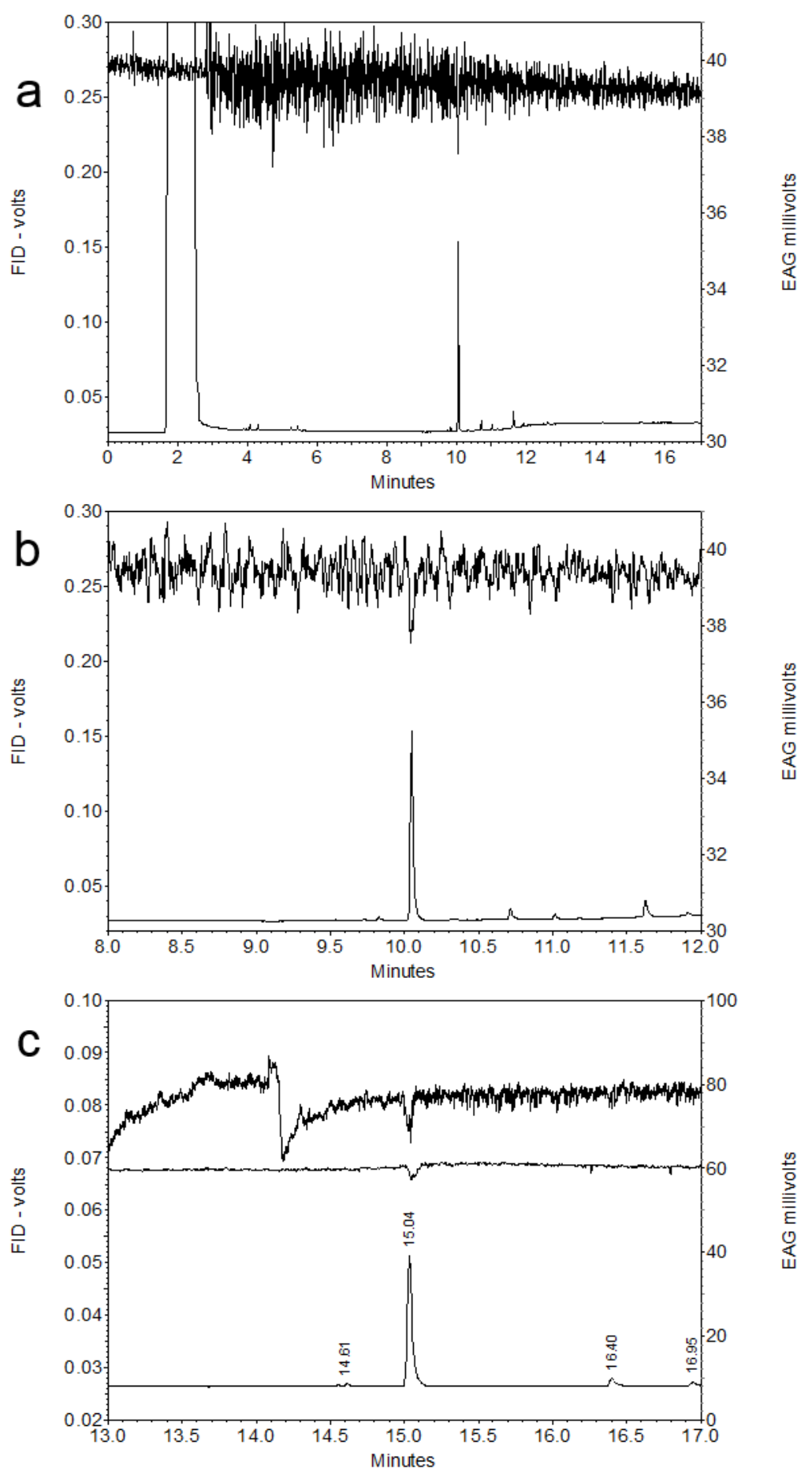


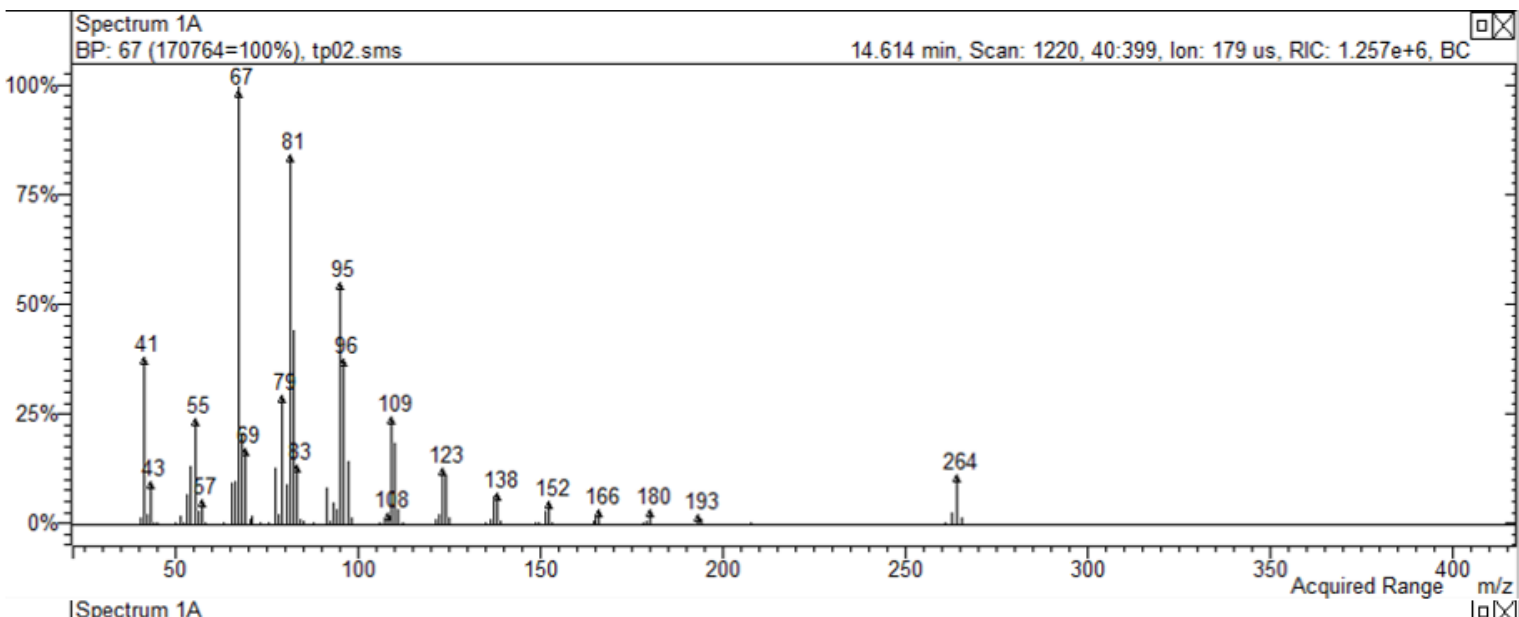

Spectrum $1 \mathrm{~A}$
BP: $67(53652=100 \%), 6919 \mathrm{~h} . \mathrm{sms}$ 14.415 min. Scan: $1179,40: 399$ Ion: 682 us. RIC: 405071 , BC

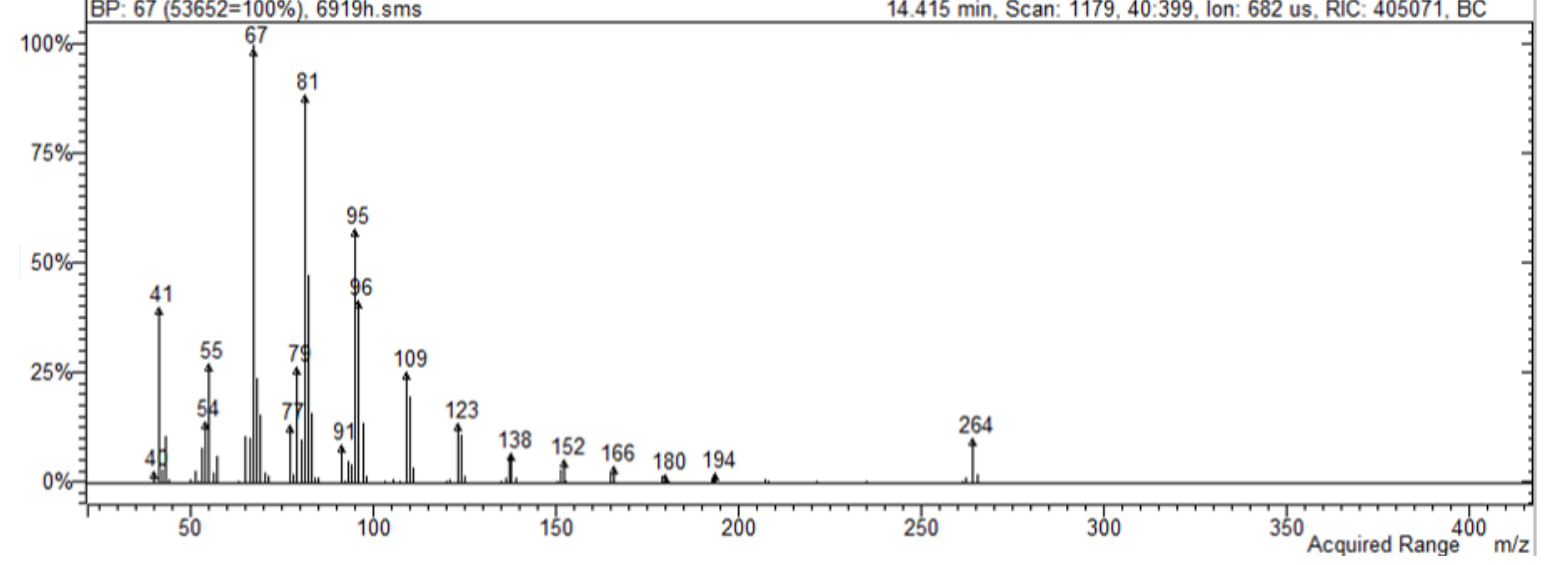




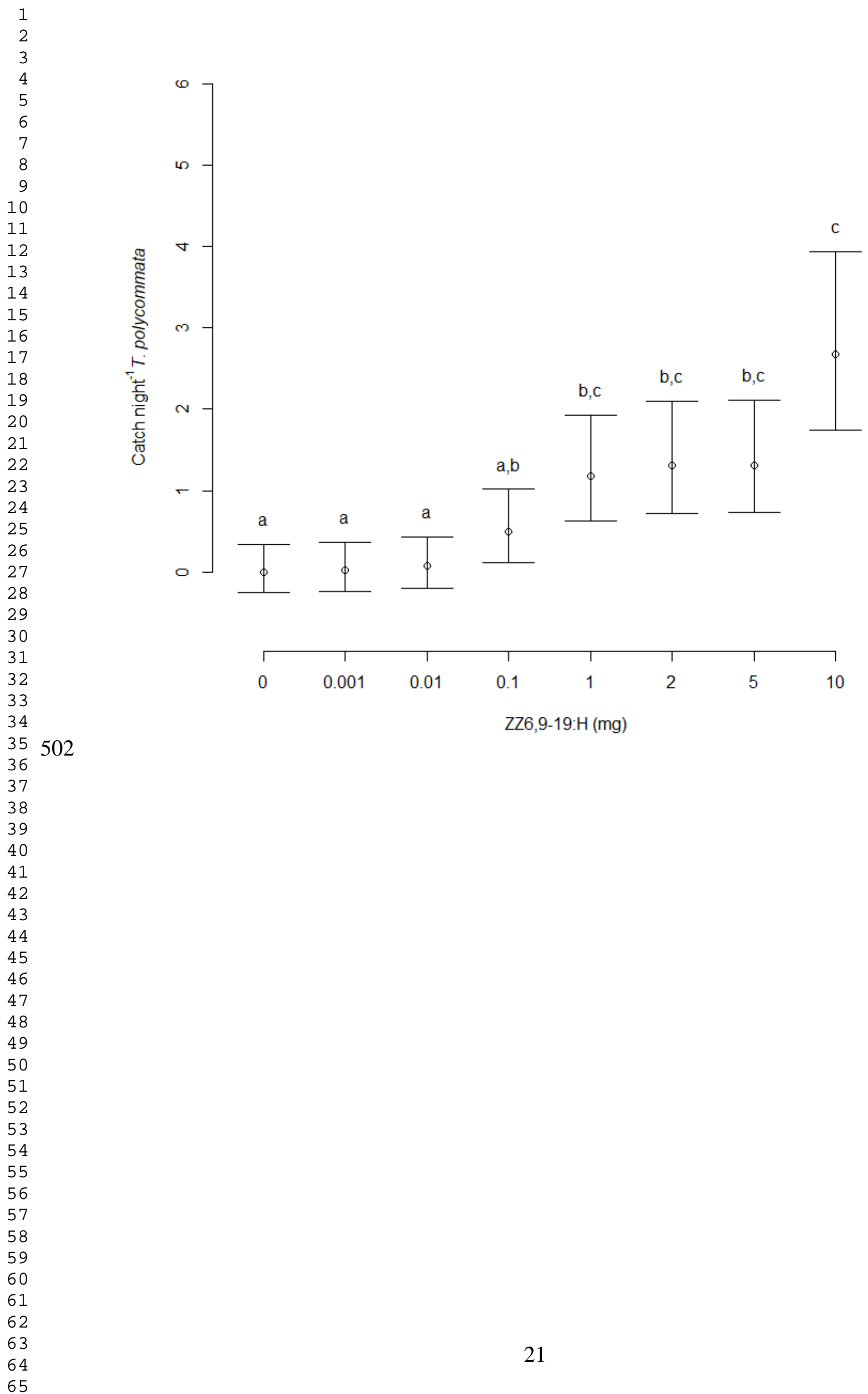


1

2

3

4

5

6

7

8

10

11

12

13

14

15

16

17

18

19

20

21

22

23

24

25

26

27

28

29503

30

31

32

33

34

35

36

37

38

39

40

41

42

43

44

45

46

47

48

49

50

51

52

53

54

55

56

57

58

59

60

61

62

63

64

65

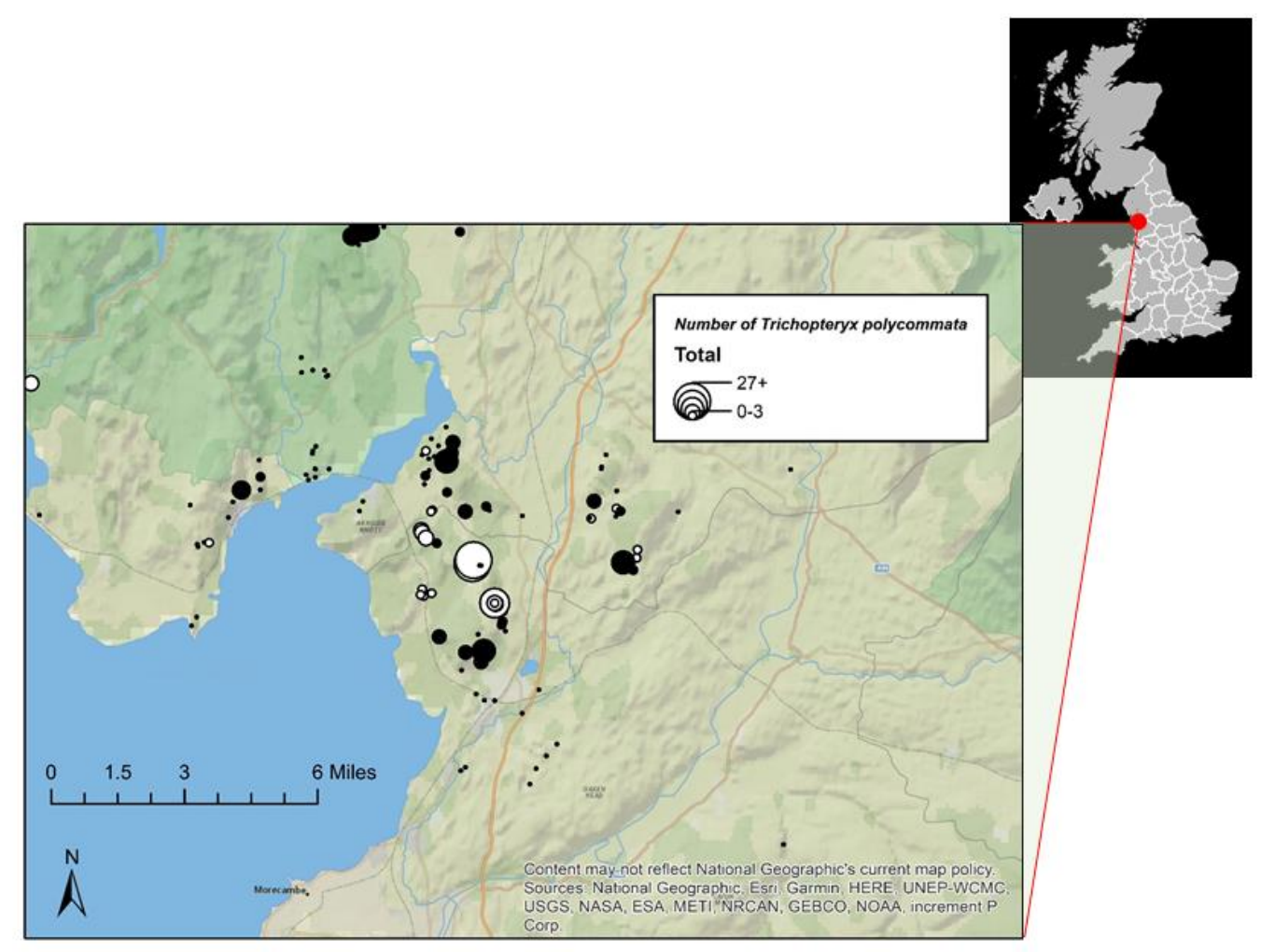


Updates figures provided as ppt (can also be provided as individual tiffs on request)
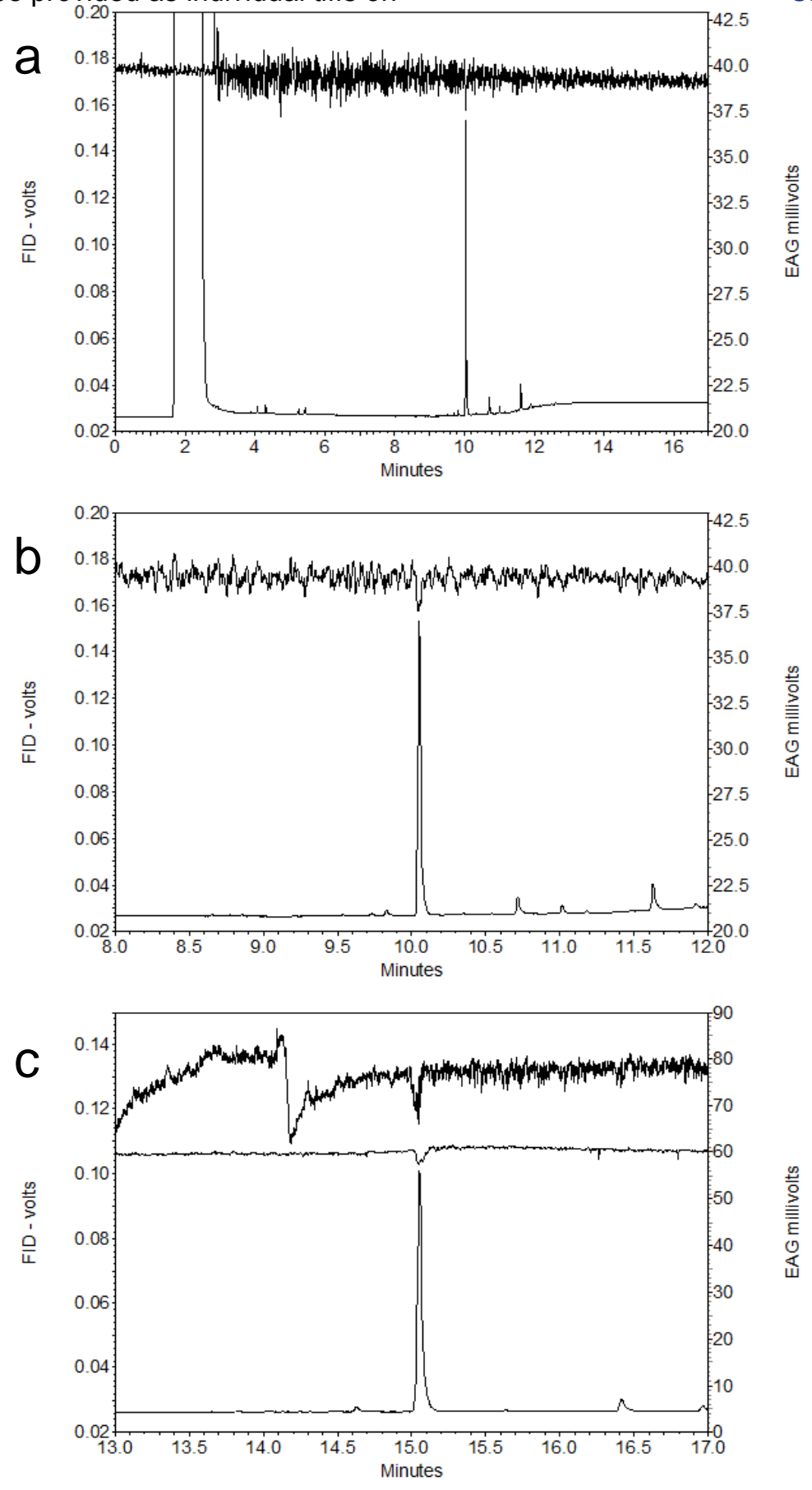


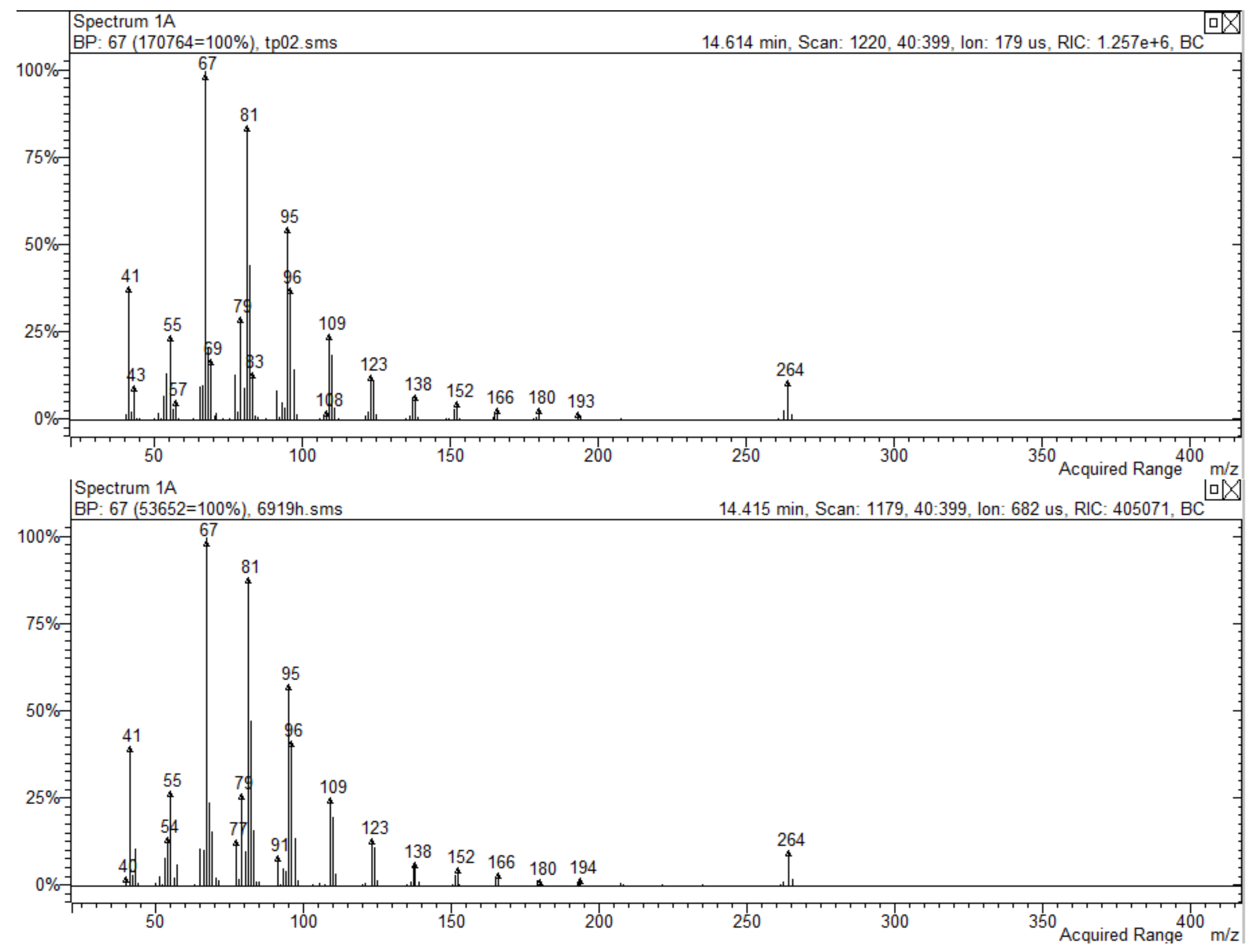




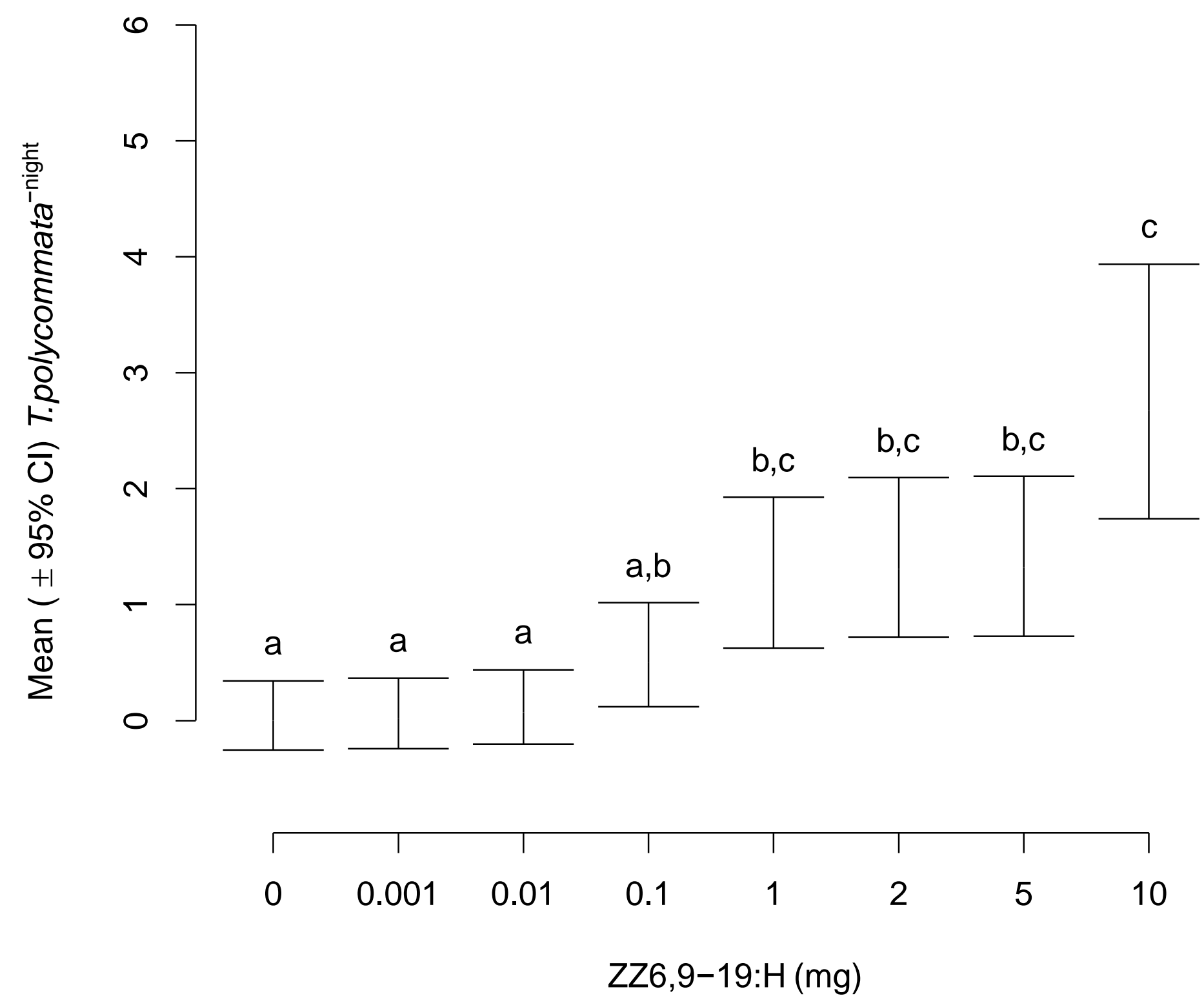




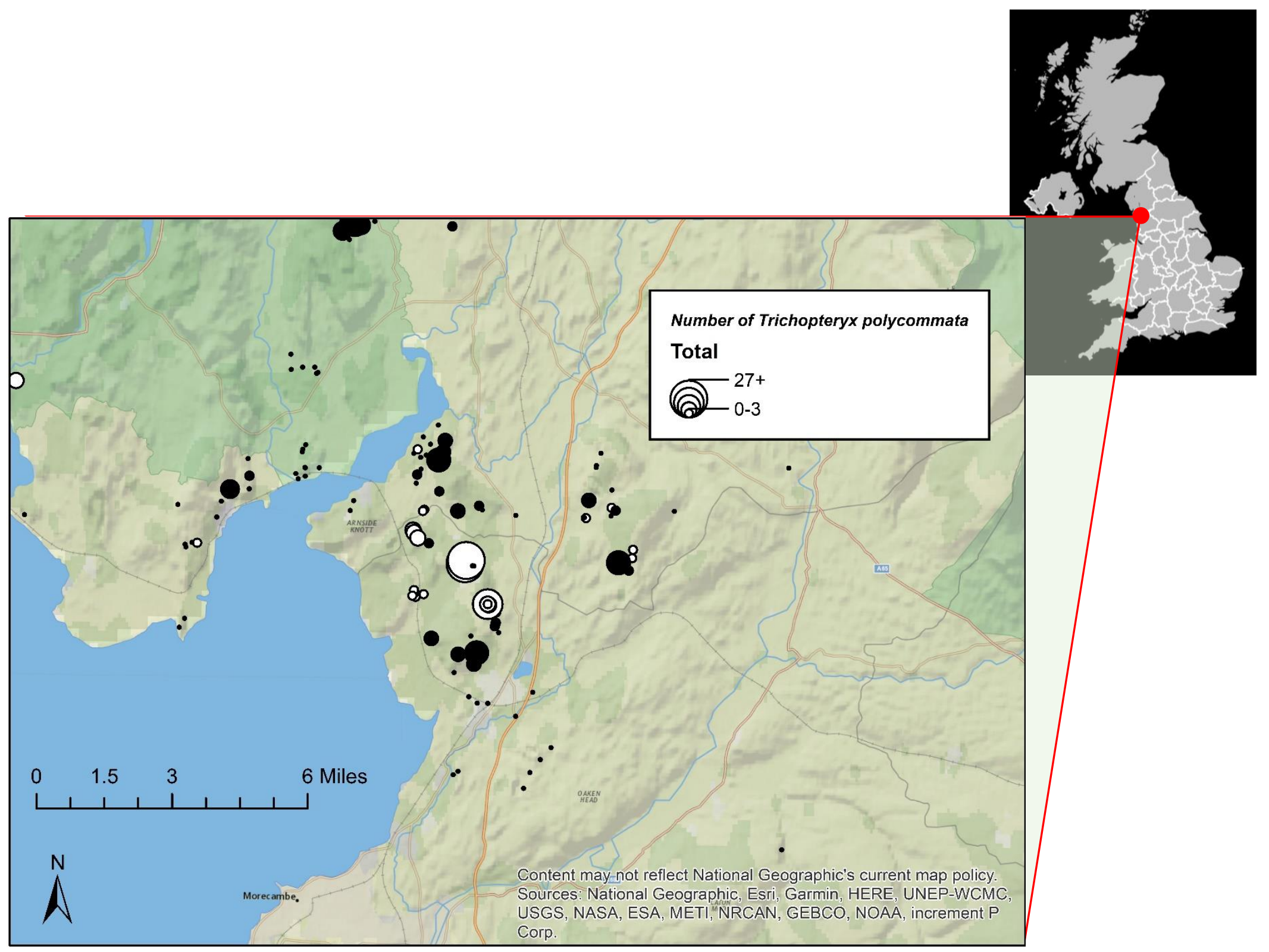

